\title{
A Arquitetura como organismo e processo
}

Giuseppe Strappa. Università degli Studi "La Sapienza" di Roma, Itália.

Tradução: Higor Ribeiro da Costa. (1) Universidade Estadual de Maringá, Programa de PósGraduação em Arquitetura e Urbanismo, Maringá, PR, Brasil. E-mail: chr94@ outlook.com

O texto a seguir foi publicado no livro 'Nuovo Realismo/Postmodernismo. Dibattito aperto fra Architettura e Filosofia' (fig. 1), de Paola Gregory (Roma, Officina Edizioni, 2016, pp. 163172). Seu autor, Giuseppe Strappa, é hoje um dos nomes mais proeminentes da escola italiana de morfologia urbana. Neste texto, Strappa demonstra como a arquitetura faz parte de um contexto amplo, em que as edificações e as cidades são geradas por meio de processos formativos em diferentes escalas, e que é necessário compreender e sintetizar o legado arquitetônico que recebemos do passado, e os novos materiais e tecnologias que surgem a cada dia (nota do tradutor).

\section{A Arquitetura como Organismo e Processo}

Participo deste debate como arquiteto e docente de projeto. Portanto, resguardo-me de entrar no mérito de considerações que dizem respeito a uma disciplina complexa e muito diferente da minha, como a filosofia. Gostaria, porém, de fazer algumas considerações que podem expor o ponto de vista, certamente parcial, de um projetista.

Direi desde já que sempre desconfiei um pouco do recente entusiasmo pelas disciplinas filosóficas, muitas vezes demonstrado pelos arquitetos. Não que a filosofia não tenha que ver com a arquitetura, obviamente. Uma vasta literatura demonstra o contrário, das reflexões de Ludwig Wittgenstein àquelas de Martin Heidegger e às de Jaques Derrida. Ou como o trabalho de alguns colegas que se dedicaram com grande competência ao tema, como Paola Gregory. Certamente a filosofia também tem lugar certo no grande crisol dos materiais que os arquitetos empregam, mais ou menos desenvoltamente, para construir o próprio corpus disciplinar - que hoje, todavia, parece um collage bizarro de conhecimentos discrepantes.

Observando bem, no mundo em que vivemos nada é estranho à arquitetura, que possui uma natureza própria, apaixonada, empática, indagadora, formada através de uma prática que, sintetizando coisas e ideias, talvez seja a característica específica da nossa área, do nosso ‘ofício'! Por essa razão, penso que a verdadeira questão epistemológica na arquitetura não é tanto a busca ansiosa pelo escambo entre as disciplinas - para nós desde sempre necessário e inevitável -, quanto uma delimitação, um reconhecimento lógico e metodológico do cerne científico da pesquisa e da prática projetual.

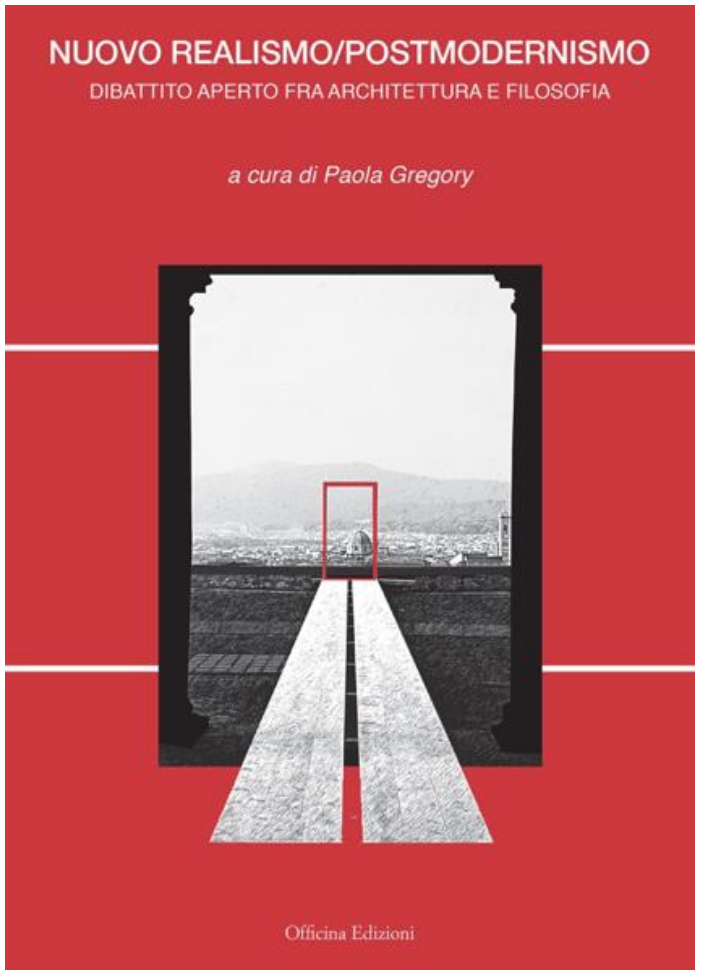

Figura 1. Capa do livro de Paola Gregory (editado pelo autor) (fonte:

http://www.philarch.org/it/. Consultado em junho de 2019).

Por isso, creio que o tema abordado neste encontro - o relacionamento com a realidade, da qual a arquitetura não pode ser um mero espelhamento - se coloque em uma zona historicamente determinada e acometa diretamente nosso trabalho. Isso diz respeito, a meu ver, às condições nas quais 
trabalhamos diariamente - e sobre as quais ocorre fazer uma séria reflexão.

Há poucos dias, por ocasião da abertura do ano acadêmico na Normale di Pisa, ${ }^{1}$ Salvatore Settis colocava o problema das formas de comunicação - reais ou virtuais - a propósito dos objetos expostos nos museus. Citando o livro do historiador Steven Conn intitulado nada menos que 'Do museums still need objects?',$-{ }^{2}$ Settis laicamente notava a crescente desconfiança na capacidade do objeto de transmitir conhecimento. Segundo ele, as tecnologias informáticas possuem uma verdade que não quer ser equivalente àquela da coisa real; uma verdade que pretende pôrse como uma realidade de grau superior.

Assim, defronte ao turbilhão de informações que um simples computador pode fornecer, $\mathrm{o}$ objeto torna-se monótono, no sentido literal do termo.

Provavelmente isso é verdadeiro; e, como notado, considerações como essas parecem ter aberto - por extensão - novos horizontes às pesquisas feitas por arquitetos. Pesquisas, porém, que se concluem, invariavelmente, em êxitos analógicos, sem atacar a essência do problema.

Se essa estrada é oportuna ou não, depende da definição que damos à arquitetura. Em sua participação, Renato Capozzi afirmou que devemos ter a coragem de exprimir a nossa própria definição de arquitetura - pois, de outro modo, não nos entendemos. Assim, buscarei fazê-lo.

Sei que a minha opinião a esse respeito não é compartilhada por alguns colegas, mas creio que a dificuldade deste debate esteja precisamente na explicação do papel da arquitetura como disciplina. Por definição, a arquitetura é estritamente ligada à noção de materialidade do nosso ofício - noção complementar àquela de processualidade; ligada ao valor do ato julgado enquanto concluído, independentemente de propósitos e conjunturas que o determinam.

Podemos discutir se esse liame pode se chamar de realismo ou não - e como esse liame se coloca entre outros tantos 'realismos'. Porém, creio que o evidente processo de abstração dos dados concretos próprio da nossa área - não constitui uma nova estrada, mas um dos problemas ainda urgentes da arquitetura contemporânea.
Certamente a arquitetura também é comunicação, arte, mercado. Mas, por definição, a arquitetura não representa, comunica ou reflete a realidade: ela é $a$ realidade. Arquiteturas são os espaços e as paisagens dentro das quais nós vivemos. São as construções, as estradas, as praças que nós habitamos.

Mesmo o desenho mais abstrato tem sentido arquitetônico se se relaciona com um projeto de transformação, com uma ideia de futuro. $\mathrm{O}$ valor que possui em si é uma outra coisa.

Creio que, por mais fluido que possa ser hoje o centro das disciplinas, e por mais incertos que possam ser seus limites, a arquitetura mais do que outras áreas do conhecimento deve redefinir seu próprio estatuto e suas especificidades.

Para podermos cultivar novas formas de combinação entre as diversas áreas, devemos refletir sobre as especificidades, sobre os caracteres que distinguem o nosso trabalho. $\mathrm{E}$ isso, precisamente, porque sua natureza sincrética corre o risco de se perder sob o ataque de tantas especializações com os quais ela tende a se identificar. O fascínio que estas áreas específicas exercem sobre os arquitetos é mais um dos nossos problemas.

Naturalmente, o projeto também está dentro dessa especificidade concreta da arquitetura. O projeto faz parte da realidade da arquitetura.

Peço permissão aos filósofos para, nesse momento, tentar interpretar o papel do projeto - à luz do que foi dito aqui por Maurizio Ferraris sobre a noção de documentalidade. ${ }^{3}$ Sob esse ponto de vista, o projeto é um objeto social, mas é-o somente enquanto produto que não resulta apenas do trabalho do arquiteto - como observava Franco Purini. Diversos atores, como setor financeiro, contratantes, normativas, intervêm na definição de um projeto, segundo um procedimento que tem seus próprios costumes, regras e rituais como prática de negociação e mediação. A arquitetura não é apenas processo, mas também procedimento; e se insere numa sequência de normas e formalidades. Às vezes, os usuários finais intervêm em algo, e, só por último, o arquiteto. A conclusão é um contrato. Essa é, se quisermos colocar assim, a parte imaterial - e nem por isso menos concreta - da realidade da arquitetura, que, 
no fim, é traduzida pelo projeto e registrada criticamente em sua redação gráfica.

Tal representação gráfica é um registro que tem diversas formas de circulação. Uma das possíveis formas de comunicação e escambo é aquela administrativo-burocrática. Outras formas de circulação também ocorrem, como aquela técnico-administrativa, ou como aquela estético-artística, que tem um circuito próprio - que é o da crítica, das publicações, etc. Certamente todas são formas de registro. Porém, para o arquiteto, o artefato é uma outra coisa: é o modo através do qual a imaterialidade do contrato torna-se, concretamente, uma matéria à qual dar forma.

E, assim, chegamos ao cerne do problema. Nós nos ocupamos de forma. Isso sob dois aspectos aparentemente divergentes.

O primeiro é aquele da percepção, da

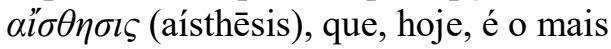
cultivado pelos arquitetos em suas modas. Modas que, de tempos em tempos, são ligadas à arte ou à ciência. Veja-se, por exemplo, a recente tendência em direção às neurociências. $\mathrm{O}$ segundo aspecto, bem mais complexo e menos cativante, é o da

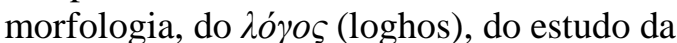
forma como aspecto visível de uma estrutura e das escolhas que dela derivam; a forma como formação que pressupõe um processo formativo que pode ser conhecido e indagado racionalmente. ${ }^{4}$

Essa subdivisão, porém, é reducionista. Ela exprime, na realidade, os polos de uma díade de termos opostos e complementares. Uma das definições de forma mais pertinentes aos estudos de morfologia - proposta precisamente por um estudioso de estética, Luigi Pareyson - demonstra isso.

Para ele, a forma é um organismo e, enquanto tal, é formada e formante, com leis próprias, internas, que ligam as partes em uma unidade. Para nós, esta definição é de grande interesse; e é tudo, menos neutra.

Isso significa ler o território como organismo territorial - como arquitetura na qual cada elemento se vincula ao outro numa relação de necessidade - ligado ao relevo e ao uso do solo. Significa reconhecer as capacidades formativas próprias do território, mesmo que suas condições estejam aparentemente fragmentadas e dispersas; reconhecer a atitude de reconstruir uma nova organicidade, ainda que instável. E isso considerando a paisagem não apenas em seus aspectos ligados à percepção, mas como aspecto visível de estruturas territoriais em transformação.

O mesmo vale para o organismo urbano - em diversas escalas -, para os tecidos edificados, para os edifícios: a forma da cidade como processo em desenvolvimento e em contínua evolução. Mesmo os edifícios podem ser vistos como organismos edilícios, nos quais a forma é o êxito de um processo permanente de transformação. Isso da matéria ao material, aos elementos, estruturas e sistemas que colaboram entre si para formar - dar forma - à realidade construída.

Portanto, o aspecto da arquitetura que percebemos pode ser considerado como um estado provisório de equilíbrio dentro de um desenvolvimento contínuo, de um processo de transformações que não para. A obra arquitetônica é seu próprio processo de formação - que não se interrompe, mas que encontra uma unidade e completude temporárias, um momento de equilíbrio no qual 'a forma se acalma e se recolhe em seu conjunto'. 5

Esta noção de forma-formação tem consequências diretas no projeto e no ensino de projetação. Buscarei expor o problema precisamente de um ponto de vista didático aspecto particular que, a meu ver, explica bem as condições gerais nas quais operamos.

Nossos livros de arquitetura moderna e contemporânea deveriam expor aos estudantes como os modos de produção atuais se formaram e quais os seus problemas. Porém, na realidade, tais livros constituem interpretações de interpretações desvinculadas dos dados concretos. No cerne de tais livros, raramente encontramos a fisicidade das obras de arquitetura, de construções inseridas no grande fluxo das transformações em andamento. Ao contrário, encontramos figuras exemplares de arquitetos e seu modo pessoal, heroico, de produzir ideias e intuições - de produzir o conceito que outros irão traduzir em construção. $\mathrm{Ou}$ seja, essa ainda é a história consoladora, a 'história monumental' de que falava Nietzsche: a história do passado exemplar, mesmo recente, e dos modelos a imitar. Ao invés disso, seria útil conhecer a realidade construída em sua evolução concreta, prática. 
Refletindo sobre ela, é possível construir a teoria - como tentarei explicar.

Nesse ponto, nossa Faculdade possui uma grande tradição. Tradição, porém, já abandonada na prática.

A 'crítica operativa' de Bruno Zevi e a 'história operante' de Saverio Muratori são aspectos diversos do problema comum de leitura da história. História que também é história do espírito, mas voltada ao mundo material das ações humanas. Voltada aos acúmulos de experiências, explorações e experimentos sobre o modo de edificar e habitar o espaço.

Na realidade, há algum tempo, também a arquitetura se tornou a sede de um processo de progressiva separação - assim como os objetos de museu discutidos por Settis. Nós nos afastamos gradualmente das coisas que deveriam ser a matéria mesma da interpretação.

Esse fenômeno não é de hoje. A exegese do texto desapareceu. O estudo do construído de fato, do edifício, a análise da formação do seu significado - que muitas vezes contém também a explicação de sua poesia - jamais aparece, se não com poucas exceções. Essa operação, em teoria, é delegada a outras disciplinas, 'complementares' ao projeto.

Além disso, mesmo que a arquitetura seja sincrética por natureza, a sua ciência não é a soma de outras ciências. Por isso, o arquiteto deveria extrair um sistema próprio de conhecimento a partir da exegese do texto. Texto que, para nós, é o mundo construído em desenvolvimento, as cidades, o território, vistos em seu contexto histórico e social. Isso serviria para retornar à origem das coisas, aos verdadeiros problemas da nossa atividade. Talvez nossos amigos filósofos fiquem horrorizados, mas, para os arquitetos, a teoria não é uma série de princípios gerais, racionalizados e rigidamente coerentes entre si; princípios dos quais deduzir logicamente indicações de como agir. É uma coisa muito menos cristalina. É estratificação de experiências, generalização daquilo que se faz, que serve em um certo momento da atividade positiva do projetar: é útil para refletir sobre o próprio agir, para dar coerência e também para explicar aquilo que se está produzindo.

Em última análise, para um arquiteto, a teoria é ainda a tentativa de sistematização da experiência que, com muito trabalho, tenta trazer o aspecto fragmentado e particular de cada gesto à totalidade do conhecimento, por mais mutável e contraditório que esse trabalho possa ser na condição contemporânea.

Não é por acaso que, no passado, cada teoria tinha sempre uma reflexão prática - cada tratado apresentava uma parte de manualística.

É certo que o esforço de transformar em cosmos ordenado o caos indomável das coisas, que não se deixam engaiolar em alguma taxonomia ou lei, é fadado ao fracasso - sempre foi, não apenas na condição contemporânea. Mas o desejo por aquela ordem - que, de todo modo, termina por incidir sobre a realidade, ordem da qual se espera uma forma de felicidade qualquer é a essência pungente e irrenunciável do projeto. Essência sem a qual cada esforço é destinado a se perder, e sem a qual toda escritura se destina a não deixar vestígios.

As múltiplas maneiras de ver as coisas que a teoria contém e exprime - com todas as incoerências que pode conter - são todas verdadeiras de algum modo, são uma constatação. Tenho comigo que a atual renúncia à generalidade é uma dolorosa perda para nossa disciplina. Generalidade que é capaz de produzir gêneros e, a partir deles, gerar o particular; e renúncia em nome da impossibilidade - no mundo contemporâneo - de um sistema unificador.

Para sustentar essa afirmação, trarei, em termos concretos, um exemplo que diz respeito aos materiais e às técnicas de arquitetura.

Foi precisamente esse processo de crescente abstração do mundo com o qual a arquitetura se comunica, junto com a progressiva especialização das disciplinas que concorrem para o projeto, que induziu a considerar os materiais, os elementos, as estruturas que dão forma à arquitetura como meras traduções de um processo ideativo: execução e realização. A consequência é que os estudantes - na falta de uma visão geral do problema - 'sofrem' hoje a técnica como um pesado comprometimento [de suas ideias], uma sofrida dicotomia entre a subjetividade da ideação e a objetividade da realidade material. 
Ao contrário, o reconhecimento de uma inelidível materialidade da arquitetura deve nos levar à realidade concreta do nosso ofício. Realidade da qual, hoje, ocorre recomeçar. Creio que estamos diante de uma potencial regeneração da arquitetura regeneração da qual nem sempre temos plena consciência. Hoje, a indústria produz uma espécie de segunda natureza. Não produz apenas materiais, mas produz matéria. Matéria parcialmente desconhecida, mas na qual nossa consciência deveria reconhecer a atitude, a predisposição de fazer parte do ciclo da arquitetura. Estamos diante das condições do homem primitivo em face do ambiente desconhecido que o circunda. Ele pôde reconhecer na argila a atitude de se tornar tijolo, ele reconheceu a disposição da pedra em se fazer parede - o que originou uma cultura plástico-muraria -, e distinguiu nas árvores possíveis pilares e traves - que propiciaram a formação de um mundo elástico-lígneo. É a consciência do homem que deveria hoje, mais uma vez, decidir que aquela matéria tornar-se-á 'matéria assinalada', material cuja finalidade é definida pelo uso, designado por um projeto. Processo que não é simplesmente de transformação física! Os materiais modernos deixarão vestígios se os soubermos inserir criticamente no grande processo de transformações artificiais da natureza processo que é contínuo, vital -, reconhecendo seu profundo valor cultural.

Mesmo na história da arquitetura moderna, as grandes mudanças ocorreram por meio de um processo cultural, e não simplesmente através de descobertas e invenções. Foi o caso do concreto.

Não fora por acaso que a pesquisa de François Hennebique - reconhecidamente o pai do concreto armado - tenha começado do seu trabalho como restaurador de catedrais medievais, precisamente no coração de um contexto pertencente ao mundo gótico e a uma área cultural elástico-lígnea. Hennebique empregava os primeiros elementos pré-fabricados em concreto para substituir as traves de madeira dentro de sistemas discretos e seriais. Através da relação direta com os materiais, ele progressivamente tomou consciência de como a nova matéria - uma pedra artificial -, unida ao ferro, poderia dar origem a um material diferente e novo. Tomou consciência de como era possível estabelecer uma relação de colaboração e solidariedade entre os diversos elementos. Tomou consciência de como a nova solidariedade entre as partes dava origem à transmissão de novas solicitações mais complexas, que requeriam que cada elemento fosse ainda mais congruente e proporcional ao próprio papel. Observação que permitiu a solução dos novos sistemas hiperestáticos.

Congruência e proporção: os mesmos termos e critérios que o arquiteto-artista da épocapouco interessado com problemas estruturais - empregava na composição de fachadas e plantas estavam para ser usados também pelos engenheiros no dimensionamento das estruturas; demonstrando a substancial unidade da operação projetual. As mesmas definições podiam ser empregadas para ler a gradual predisposição à colaboração dos elementos da arquitetura e a sua progressão de organicidade.

Creio que a cultura arquitetônica tenha perdido, naquele momento, uma ocasião de reconciliação entre as suas duas almas, entre a materialidade da construção e a abstração do desenho artístico.

No fim do século XIX - quando se desenvolviam os estudos sobre a elasticidade dos materiais, na esteira da interpretação 'arquitetônica' do problema proposta por Claude-Louis Navier -, arquitetos e engenheiros não souberam (ou não puderam) compreender como seu trabalho poderia ser não apenas complementar, mas substancialmente idêntico.

O termo físico de 'congruência' - que os engenheiros começavam a empregar na solução de problemas científicos - juntava ao mesmo tempo análise do comportamento dos materiais e forma arquitetônica, juntava solicitações e deformações ao desenho da obra. Outros aspectos do conhecimento científico pareciam propiciar uma nova unidade de conhecimentos que, sob o impulso da especialização, porém, percorriam estradas paralelas e rigorosamente autônomas; como, por exemplo, a noção de vínculo, que contribuía para explicar em termos racionais um dos aspectos da ideia de nó que os arquitetos sempre tinham percebido e definido em termos de linguagem e códigos.

Muitas das considerações sobre a conformidade e sobre a medida entre as partes de uma construção - elaboradas pelos 
tratadistas por séculos - encontravam, também, uma relação com a física e com a matemática - ainda que parcial.

Demonstravam como intuição e ciência podiam se tornar dois aspectos de um mesmo processo de conhecimento: expressão da 'arte da construção'. A incapacidade de compreender esse momento de síntese em potencial era, na realidade, a consequência de uma transmissão de conhecimentos fundada sobre uma divisão funcional de novos equilíbrios sociais e econômicos, como Schopenhauer destacava com profética clareza. ${ }^{6}$

Se realmente quiséssemos renovar as escolas de arquitetura, o seu estudo deveria indicar o retorno à realidade, deveria demonstrar como a matéria é parte constituinte da própria invenção. O projeto como expressão artística. Não apenas manifestação romântica do 'eu' individual, mas a arte da síntese, da capacidade ativa de, ao mesmo tempo, conhecer e interpretar.

Ainda assim, hoje, mesmo nos estudos especializados sobre construção, os termos físicos do problema que estão diretamente ligados à forma são sempre mais mediados e escondidos pelo aspecto matemático.

Gostaria de concluir recordando uma conferência de Edoardo Benvenuto no Politecnico di Milano. Benvenuto, teólogo e especialista em estruturas, autor de obras de filosofia da ciência singulares, ${ }^{7}$ afirmava que '(...) a integração entre arquitetura e racionalidade científica supera o momento instrumental e mira no próprio significado da obra arquitetônica'.

Benvenuto sustentava a ideia de que o arquiteto deve retornar ao contato direto com as coisas mais elementares, convocando-se a uma espécie de nova física aristotélica. Sustentava que há um mundo vasto e novo por descobrir nos simples elementos da arquitetura, na trave e no pilar, no seu sentido construído e simbólico - mesmo que, a respeito de traves e pilares, tudo já tenha sido escrito por físicos e engenheiros.

\section{Notas}

${ }^{1}$ S. Settis, Reale o virtuale?, https://www.youtube.com/watch? $\mathrm{v}=\mathrm{LpBXuyJXYWY.}$

${ }^{2}$ S. Conn, Do Museums Still Need Objects? The Arts and Intellectual Life in Modern America, University of Pennsylvania 2010.

${ }^{3}$ Cfr. M. Ferraris, Documentalità. Perché è necessario lasciar tracce, Roma-Bari 2009.

${ }^{4}$ Cfr. G. Strappa, L'architettura come processo. Il mondo plastico murario in divenire, Milano 2014.

${ }^{5}$ L. Pareyson, Estetica. Teoria della formatività, Firenze 1974.

${ }^{6}$ A. Schopenhauer, Ueber die UniversitätsPhilosophie, Berlin 1851 (trad. it. La filosofia delle università, Milano 1992).

${ }^{7}$ E. Benvenuto, Materialismo e pensiero scientifico, Milano 1974; Id., La scienza delle costruzioni e il suo sviluppo storico, Firenze 1981.

\section{Referências}

Strappa, G. (2016) L'Architettura come organismo e processo. Em: Gregory, P. (ed.) Nuovo Realismo/Postmodernismo. Dibattito aperto fra Architettura e Filosofia. Roma, Officina Edizioni, pp. 163-172. Disponível em: https://www.academia.edu/35319582/LARCHITE TTURA_COME_ORGANISMO_E_PROCESSO _in_P._Gregory_editor_Nuovo_realismo_postmo dernismo._Dibattito_aperto_tra_architettura_e_fil osofia._Officina_Roma_2016 [Consultado em: junho de 2019]. 